\title{
Changing paradigms in agricultural research
}

\section{Significance of end-user involvement}

\author{
T. Laxmi, P.S. Janaki Krishna and G. Pakki \\ Reddy
}

\begin{abstract}
In general, developments at new frontiers of science and technology exert significant impacts on the way the research is thought about and executed. Agricultural RED is no exception to this. The discovery of the double-helical model of DNA by Watson and Crick in 1953 and the later developments in the field of biotechnology made agricultural research more knowledge- and capital-intensive. Furthermore, with the liberalization of economies the world over, the private sector emerged as a key player in agricultural research. While public sector institutions continue to concentrate on meeting ever increasing food demands, the private sector tends to focus on crops that would generate profitable returns, thereby raising concerns about meeting the needs of small and marginal farmers. This paper reviews various paradigms that are evolving in agricultural research and answers the following questions: (a) what are the different paradigms in agricultural research; (b) how are these paradigms affecting the priorities for research; (c) what is the impact of such shifts in priorities in agriculture on the variety of end-users; and (d) are there any institutional arrangements to cater for the needs of the small and resource-poor farmers whose needs are bypassed by these shifts in priorities? Following this, the innovative model of the Andhra Pradesh Netherlands Biotechnology Programme that aims to produce need-based technologies is discussed.
\end{abstract}

Keywords: agricultural research; biotechnology; research paradigms; participatory approaches; end-user involvement; Andhra Pradesh Netherlands Biotechnology Programme

T. Laxmi is a Researcher with the Centre for Research on Innovation and Science Policy (CRISP), \# 8-2-608/1/2 Karama Enclave, Road No 10, Banjara Hills, Hyderabad 500034, India. E-mail: Laxmi.thummuru@gmail.com. P.S. Janaki Krishna is a Consultant for the Andhra Pradesh Netherlands Biotechnology Programme, Institute of Public Enterprise, Osmania University Campus, Hyderabad-500 007,India.E-mail: jankrisp@yahoo.com; hyd2_btuipe@sancharnet.in.G. Pakki Reddy is Professor and Coordinator of the Andhra Pradesh Netherlands Biotechnology Programme. E-mail: gpakkireddy@hotmail.com; hyd2_btuipe@sancharnet.in.

Agriculture forms the backbone of the economies of most developing countries, with the majority of the population depending directly or indirectly on agriculture and allied occupations. This is particularly the case in India, where over $70 \%$ of the population depend on agriculture for their livelihood. But the area of per capita arable land, which is crucial for agriculture, declined from 0.5 hectares in 1960 to 0.27 hectares in 2000, and is likely to decrease further to 0.1 hectares by 2030 (Khush, 2002). If the growing food demands within the limited land resources are to be met, advancements in science and technology (S\&T) need to be fully utilized.

The green revolution (GR) package, which is often cited in this regard, made the country self-reliant in the 
production of food grains. This was achieved through systematic and planned interventions during the 1960s by, for example, the introduction of seeds of high-yielding varieties (HYVs) developed in public sector institutions, the efficient use of chemical-based pesticides and fertilizers, improved irrigation and institutionalized credit facilities. During this period, national and international public sector institutions played a crucial role in agricultural research, developing and releasing many new varieties. However, this technological package, which favours irrigated ecosystems, was often criticized for widening regional economic disparities in the country, as its success was limited to the irrigated ecosystems. It has also been under attack for causing environmental and ecological imbalance of the ecosystems, as it introduces more chemicals into the environment (eg those resulting from the high applications of chemical pesticides and chemical fertilizers that are needed for HYVs).

Consequently, over a period of time, yield gains from the GR package reached a plateau and there was then a growing need to explore alternatives to meet the increasing food demands. Biotechnology is seen as a viable option to increase agricultural productivity (see Syngenta Website). Norman Borlaug (1997), a pioneer of the green revolution, makes the following observation on the potential of biotechnology in agriculture:

'Even if the current per capita food consumption stays constant, population growth would require that world food production increases by 2.6 billion gross tonnes or 57 per cent - between 1990 and 2025. However if diets improve among the destitute who live in hunger, estimated to be 1 billion people living mainly in Asia and Africa, world food demand could increase by 100 per cent - to above 9 billion gross tonnes - over this 35 year period .... to meet the projected food demands ... the average yield of all cereals must be increased by 80 percent during 1990 and the year 2025...Genetic engineering will permit another 50 per cent increase in yields over the next 35 years.'

The liberalization of economies and the decline in economic resources available to public sector institutions to carry out research, and the capital- and knowledgeintensive nature of biotechnology research paved the way for the private sector to play a key role in agricultural research. This trend has serious implications for the way agricultural research is conceptualized and executed. Given this, we describe various trends and models that are concept-based on different patterns of technology development and transfer in agriculture. Also, a brief description of the 'Andhra Pradesh Netherlands Biotechnology Programme (APNLBP)' is provided to demonstrate the utility of participatory models in technology development.

\section{Models of technology development and transfer}

\author{
Model I: The public sector as producer and disseminator \\ of technology
}

The role of national and international public sector institutions in developing appropriate technologies to cater to the needs of diverse sections of the farming community is discussed in this model. Public sector institutions the world over have long played a significant role in agricultural research in developing technologies and varieties with the needs of the farmer in mind. These institutions, whether at national level (eg the Indian Council of Agricultural Research - ICAR, institutes or state agricultural universities) or at international level (eg the Consultative Group on International Agricultural Research - CGIAR), implicitly follow the top-down approach to technology development, which was adopted in the industrial and green revolution technologies. Such 'transfer of technology' (TOT) models, characterized by the top-down approach, require that all the key decisions are taken by scientists and based on experiments under controlled conditions at research stations. The technologies are then transferred to extension services and then to farmers; and it has to be said that this approach has been successful in increasing unit output. In the rural situation, however, which differs radically from the conditions found in the experimental situation, the results are not so clearly advantageous (Pimbert, 1994). The centralized plant breeding of the green revolution yielded its best results in more favourable agricultural environments; most resource-poor farmers in marginal areas have not benefited from the improved varieties. Decades after the GR, it became apparent that the application of this non-participatory 'Northern' model in developing countries did not satisfy the needs of farmers in more marginal agricultural environments (Witcombe, 1996).

In India, the contributions of public sector institutions to agricultural research and knowledge production cannot be belittled. Agricultural research in India can be traced back to the British period of the 1880s when departments of agriculture were established at the central and provincial levels. The establishment run by ICAR, entrusted with the responsibility of developing new technologies and new varieties to suit to the needs of farmers (Balaguru, 1991) constituted an important step in state support for agricultural research.

In addition to the ICAR institutions and state agricultural universities, a variety of other universities and agencies of the central and state governments became engaged in agricultural research. However, as the funds available to public sector institutions for agricultural research declined, the liberalization of the Indian economy during the 1990s enabled private sector funds to be released into the agricultural biotechnology research sector, which also brought about a shift in ownership of the technology, thereby making research in this area more capital- and knowledge-intensive. During this transformation, the thrust and priorities of research (largely profit-motivated) were entirely changed as the ownership of technology changed hands. Thus the second model views the private sector as a profit seeker in the first instance, and tries to analyse its interest/disinterest in keeping the needs of resource-poor farmers in perspective.

\section{Model II: Private sector as profit seeker}

The three main components of agricultural research, 
namely: (i) development of high-yielding varieties, (ii) production of hybrids with improved performance, and (iii) production of genetically modified (GM) seeds, reiterate the significance of biotechnology in agricultural research (Dhar, 2002). While the public sector has a significant role in the development of high-yielding varieties, the private sector plays a crucial role in the production of hybrids and genetically modified seeds. The emphasis of the private sector is on crops with potential for profits and scope for patents for innovations. Also, the products developed through biotechnology by the private seed companies are usually more expensive than those developed by the public sector institutions. In contrast to the public sector institutions, whose priorities are more regional, the priorities of the private sector are dependent on global interests, which take them even further away from the local end-users (referred to here as small and resource-poor farmers).

As a result, there has been a mixed response to the entry of the private sector into agricultural research. Although policy makers encouraged the entry of the private sector into agriculture, mainly in the seed industry, scientists and farmers voiced their concerns, as this would lead to the privatization of agricultural research, making farmers increasingly dependent on the seed companies.

First, to secure a reasonable return on its investments, the private sector relies on intellectual property protection, which is enabled through the General Agreement on Tariffs and Trade (GATT). Although the Trade-Related Aspects of Intellectual Property Rights (TRIPS) Agreement prompts endorsement of plant breeders' rights (PBRs), the European Directive on the Legal Protection of Biotechnological Inventions prevents unrestricted access to plant genetic material for farmers and scientists. Second, in the new era of technology developments, agriculture should emphasize the employment of renewable sources of energy to promote sustainability. This new approach has to be more productive and efficient in relation to energy input (seeds, pesticides, fertilizers and mechanization) and output (harvested produce), which can be achieved through advances in molecular biology and biotechnology. Here, public sector institutions have a crucial role to play in making agricultural systems more productive, bearing in mind their long-term commitments and the active role they have played in the major discoveries in agricultural biotechnology so far (Jain, 1999).

Seshia and Scoones (2003) argue that, while the discourses on green revolution technology need to be understood in the post-colonial and cold war context, the emergence of biotechnology has been shaped by the economic reforms of the 1990s and perhaps even more so by the globalization of trade and production.

In India, because of the restrictions imposed by the licensing policy of the government operated from the 1960s, the role of the private sector in the seed industry was limited to a few companies involved in the development of superior hybrids of maize, sorghum and bajra. The Seeds Act of 1966, aimed at regulating the growth of the seed industry, specified that seeds should conform to a minimum stipulated level of physical and genetic purity and assured percentage germination, with either compulsory labelling or voluntary certification (Shiva and Ramprasad, 1993). However, the later relaxation of the provisions in the licensing policy enabled the entry of the multinationals into the seed sector. The New Seed Policy of 1988 encouraged technical and financial collaboration with foreign companies in two areas, namely: (a) identifying crops whose seed could be produced locally for export markets, and (b) producing for export markets only, including producing seed under custom production, irrespective of the indigenous availability of seed. During the initial stages of development, state-owned public sector institutions played a significant role, with more than $90 \%$ of funds being invested in the biotechnology sector.

The privatization of agricultural research in the industrialized countries gained momentum in the early 1980s, whereas in India, privatization started during the 1990s with the liberalization of the economy. The 1991 Industrial Policy identified seed production as a 'high priority industry', thus making a radical departure from the earlier policy on foreign investment. Chaturvedi (2001) observes that investment by the public sector in R\&D decreased during the two decades from 1971-91. Pray et al (2001) observe that private sector investment in R\&D has significantly increased since India took up economic reforms. The number of private seed companies engaged in R\&D increased from nine in 1985 to 40 in 1995. The corresponding growth in R\&D expenditure (in actual terms) between 1987 and 1995 was from Rupees13.1 million to 46.5 million (Rao, Hanumantha, 1987). Although private sector investment has substantially increased, there is still a dearth of strong R\&D in the private sector in developing countries. Small private companies cannot afford R\&D, which is capitalintensive. This situation hinders biotechnology development that is highly dependent on research and requires trained manpower, which, however, is available to public sector institutions and traditional universities.

Thus the demand for highly skilled workforces, and the capital-intensive and applied nature of biotechnology research necessitated the emergence of another model, the necessary collaborations for which are still in the bargaining stages in many developing countries.

\section{Model III: Public-private sector partnerships as joint producers and disseminators of technology}

The introduction of biotechnology has significant implications for the way research projects are conceptualized and executed, both by individual scientists and by the donor agencies. Rao (2002) observes that at any given time, there are at least 1,500 R\&D projects being implemented by science and technology agencies. In the initial stages of agricultural research, the projects were granted to individual scientists. As R\&D in biotechnology became more capital- and knowledgeintensive, the situation warranted a shift from individual scientist-/investigator-based research projects to multidisciplinary and multi-institutional projects involving industry as well as scientists from a traditional science background.

Thus the third model for agricultural research focuses on collaboration between scientists from the public and private sectors. In its initial stages of development, 
biotechnology has origins in university research funded by government agencies. However, the growing commercial interests created new mechanisms for interaction between public and private sectors, for which Kenney (1995) observed that three types of linkages emerged. The first type of linkage is that of the professor employed in a department starting up a company to commercialize an aspect of his or her research. However, in such cases, the stake of the individual professor in the commercial firm might create conflicts of interest between academic responsibility and personal financial gain or commitment. Furthemore, a professor might appropriate unpublished results of his/her own or of a student's research for the company in which he or she has a stake.

The second type of linkage is institutional, involving long-term affiliation between a single firm and a laboratory/university department, in which huge sums of sponsorship/endowment funds are made available to the department. The long-term contracts between the companies and researchers may carry the condition that, in return for funding research in the university, the company would have rights to the research results. The characteristic of this linkage is that the university administration can monitor the contract, but the private sector has the opportunity to shape the research agenda of the university.

The third type of interaction is the concept of the 'research centre', pioneered by the National Science Foundation (NSF) during the 1970s. In this model, biotechnology centres/institutes are formed by corporate consortia with federal or state involvement. It is often argued that the objective of these centres is to facilitate the transfer of information and know-how from scientists located in the university to the corporate sector in exchange for research funding. However, any success of this concept is largely attributable to the ability of the companies to cooperate and of the university scientists to conduct work of commercial interest to the constituent companies. Although this mode of interaction has been successful in knowledge production in biotechnology, issues of credit sharing, intellectual property protection and power relations may yet have to be resolved.

While participating researchers from the public sector institution could access research funds through these partnerships, the research agenda is most often set by the company. In the wider context, scientists in the public sector institutions, hitherto working for the good of small and resource-poor farmers, may not be able to protect any research that might more readily benefit these sections of the farming community. Thus there is a danger in this interaction of neglecting the needs of the small operators and resource-poor in society.

There exists another parallel model to these developments, however, which is being tested by people (policy makers, laboratory and social scientists, civil societies) who strongly believe in protecting the interests of the resource-poor. Below is the description of such a model.

\section{Model IV: Participatory model for technology development and transfer}

The three models discussed so far treat the end-user as a passive recipient of the technology developed. In so doing, a mismatch arises between the priorities of the end-user and the technologies that are developed. This might necessitate a reorganization of the existing intraand inter-institutional structures and an exploration of alternative paradigms for technology development with greater involvement of the end-user. In such a context, any innovations in participatory research models in R\&D must include farmers and rural people as active participants. However, these initiatives are limited to the CGIAR and National Agricultural Research Systems (NARS). The role of the donor agencies as well as the agricultural research institutes cannot be undervalued if the participatory research models are to be institutionalized and strengthened. If the appropriate agricultural technologies are to be developed, the various groups of stakeholders that share the conviction for participatory aspects of technology must together discuss the common problem areas.

Rajeshwari Raina (2003) observes (in his consideration of biotechnology) that the most important lesson from the green revolution is that technology in itself can contribute little to agricultural development unless several complementary technologies, institutions and policies are in place. Thus the conventional green revolution paradigm is forced to shift to a more ecologically just and politically sound paradigm of sustainable agriculture, involving the end-user in the process. This is even more pronounced in relation to agricultural biotechnology, since the products have hitherto been inaccessible to the resource-poor. With the failure of the TOT model in reaching out to the resource-poor, some agricultural institutions have taken the initiative to explore new strategies to enable and increase farmers' participation in technology development. Some examples include the gene bank of Ethiopia involving the farming community in the conservation of genetic diversity; participatory plant breeding and germplasm evaluation involving farmers, non-governmental organizations and scientists in Zambia and Colombia; and watershed development programmes, Farmers' Field Schools and Biovillages in India.

In the 1980s, in order to encourage the adoption of higher-yielding varieties by resource-poor farmers, scientists initiated farmer participatory research in plant breeding for grain legumes, rice, pearl millet and maize in several countries, including Colombia, India, Namibia, Nepal and Rwanda. More simple methods using plant variety selection have been used, and evaluation of the outcomes is participatory (Witcombe, 1996). Recognition of the value of this led to the introduction of the 'participatory process in technology development', popularly known as 'participatory technology development' (PTD) during the late 1980s. In this approach, farmers are recognized as partners in 'on-farm research trials'. Although the significance of the role of farmers in agricultural research was recognized during the 1980s, they are still excluded from mainstream research. Also, issues pertaining to institutionalization, cost effectiveness and sustainability of the process of PTD are yet to be answered. Broerse and Bunders (1991) suggested a new approach in participatory technology development, ie the 'interactive bottom-up' (IBU) approach, in the 1990s to overcome these constraints. The IBU approach was named deliberately in contrast to the 'top-down' approach, as the 
end-user of the technology is considered to be paramount. This approach starts with an analysis of farmers' problems, and reviews relevant scientific developments to address those needs where there is an opportunity for technology intervention. This ensures that any biotechnological development is appropriate to the capacities, knowledge, physical and social environment of the farmers (Clark et al, 2002). The Andhra Pradesh Netherlands Biotechnology Programme (APNLBP), one of the four country programmes supported by the Dutch government, is one such example, which follows the principles of IBU for tailoring technologies to suit to the needs of resource-poor farmers (Pakki Reddy and Janaki Krishna, 2002).

\section{Andhra Pradesh Netherlands Biotechnology Programme}

The Biotechnology Programme of the Netherlands' Directorate General of International Cooperation (DGIS) is one of the few development programmes that is directed exclusively towards biotechnology and poverty alleviation. Additionally, it has applied a participatory method to define programme priorities in four partner countries, India, Kenya, Zimbabwe and Colombia, with the involvement of scientists, government officials and the main target group: small-scale farmers. This combination provides a unique case to assess the potential of participatory priority-setting processes for biotechnology research (Commandeur, 1997). These country programmes demonstrate that the philosophy of participatory approach followed in these programmes gives scope for addressing the research problem that is appropriate to solve the problems faced by small and resource-poor farmers in their farming systems. In so doing, the technologies are tailored to suit to the needs of end-users.

Started officially in 1996, APNLBP operates in selected villages of the rainfed areas of the Mahaboobnagar and Nalgonda districts of Andhra Pradesh, a federal state in India where food grains, oilseeds, agroforestry, horticulture, animal health and production are priorities. The emphasis of the Programme is on developing appropriate and affordable biotechnologies to meet the needs of small and resource-poor farmers. Initially, the Programme was to run for a period of six years from 1995 to 2002, but based on the positive results that were attained during this phase, it was extended by another five years until 2007. The total outlay of the Programme is about US\$10 million. The responsibility for executing the Programme rests with a multi-stakeholder steering committee consisting of representatives from the national policy-making body, ie the Department of Biotechnology, Indian Council for Agricultural Research (ICAR), various state government departments, universities and representatives from NGOs. The Programme is managed by a secretariat, ie the Biotechnology Unit (BTU) hosted by the Institute of Public Enterprise (IPE), Hyderabad. The management team consists of experts drawn from multidisciplinary backgrounds in social sciences, rural development, biotechnology, agronomy and animal husbandry.

The Programme follows an IBU approach, which ensures that the research priorities are arrived at through a process of constant interaction between the scientists and farmers (Buijs, 2002). Through this approach, the Programme was able to make significant progress in developing useful methodologies by ensuring the participation of the end-user in the process of technology development, refinement and eventually its transfer to the farmers' fields. The Programme has been successful in establishing strong linkages with diverse organizations with capabilities in research, technology transfer and adaptation. The Programme is also engaged in conducting public lectures and debates in different parts of the state to create awareness of the pros and cons of biotechnology among the different stakeholders. Realizing the significance of capacity building and human resource development in biotechnology, the Programme supports postgraduate courses and refresher courses in biotechnology in selected universities in Andhra Pradesh.

The Programme has so far supported 75 research projects with a commitment of Rs320 million (approximately US\$6.4 million), which can be categorized into three groups, namely: low, middle and higher order biotechnologies, based on their technological complexity. Techniques for the production of biopesticides, biofertilizers and vermicompost (use of earthworms to prepare manure) are regarded as lower forms of biotechnology, whereas techniques for tissue culture and recombinant DNA techniques (development of transgenics) in plants represent the middle and higher order of biotechnologies respectively. So far, the major contributions of the Programme have included:

- capacity building at societal, institutional and individual level;

- establishment of a unique process in technology development and transfer;

- isolation and characterization of novel genes,

- genetic transformation in some important dryland crops;

- establishment of rural biocentres;

- entrepreneur incubation in biotechnology;

- establishing a good network of NGOs and civil society organizations; and

- creating awareness of the potential advantages of agricultural biotechnology among different stakeholders.

Based on the experience of the Programme, it is evident that the IBU approach ensures the participation of all the stakeholders, but mainly the end-users, in the technology development process. However, the process is not the straitjacket it might appear to be, and the approach varies depending on the nature of the technologies (basic to applied) and the local environment. Nonetheless, the interactive participatory process is essential for research programmes whose ultimate objective is to take the technologies to the unreached, thereby making use of local resources and encouraging local capacities (Ruivenkamp, 2003).

\section{Conclusion}

Indian agricultural research, which was hitherto 
concentrated in public sector institutions (Model I), helped in increasing food productivity and thereby the attainment of food security. However, with the increasing population, decreasing per capita land availability for agriculture, and yield gains reaching a plateau, the situation warranted exploration of new approaches in the technology. Globally, developments in biotechnology have significantly influenced research addressing the problems of food security and sustainable development. However, the capital requirements and knowledge-intensive nature of biotechnology research, coupled with the liberalization of economies, increased the participation of the private sector in agricultural research (Model II), thereby threatening the interests of the resource-poor. The decrease in funding for agricultural research in the public sector, coupled with the knowledge- and capital-intensive nature of biotechnology research and the consequent risk of monopolization of this area by the private sector, necessitated the emergence of another scenario in agriculture research with public-private partnerships (Model III), which has implications for both knowledge production and benefit sharing. The three models in agriculture research conceptualized in the present paper are based on the distribution of research activities between the public and private sectors and on the collaboration between them.

However, the inability of these models to cater to the needs of end-users, especially the resource-poor, spawned the need for alternative research paradigms (Model IV). Nevertheless, institutionalization of the alterative paradigms in agricultural research is still in its infancy. The Andhra Pradesh Netherlands Biotechnology Programme (APNLBP), which fosters one of the alternative models for technology development and transfer, ie the 'interactive and participatory model', ensures the participation of end-users in the process of technology development, transfer, refinement and finally its adoption. As the scope for greater participation and accountability for all stakeholders in this model is high, national and international organizations may consider the experiences of APNLBP for adoption with suitable modifications.

\section{Acknowledgments}

This paper is based on the experience of the Andhra Pradesh Netherlands Biotechnology Programme in the context of changing paradigms of agricultural research. The authors would like to thank the Research and Communications Division, Ministry of Foreign Affairs, Government of the Netherlands, for financial support to the Programme. The publication does not constitute an endorsement by BTU or the funding agency.

Responsibility for the content and the opinions expressed rest solely with the authors.

\section{References}

Balaguru (1991), 'National Agricultural Research System in India', Website: http:/icar.naarm.ernet.in/info/focarnotes/ tbnars 1htm.

Borlaug, N. (1997), 'Feeding a world of 10 billion people: the miracle ahead', Website: www.biotechknowledge.com/ showlib_us.php3/2339.
Broerse, J. E. W., and Bunders, J. F. G. (1991), 'The potential of biotechnology for small scale agriculture', in Appropriate Biotechnology in Small-Scale Agriculture: How to Reorient Research and Development, CABI International, Wallingford, pp 25-69.

Buijs, J. (2002), 'Shaping biotechnologies in the context of resource poor farming - a study of the Andhra Pradesh Netherlands Biotechnology Programme, India', MSc thesis submitted to Social Sciences, Wageningen University, Wageningen.

Chaturvedi, S. (2001), 'The public private debate in agricultural biotechnology and new trends in the IPR regime: challenges before developing countries', Research and Information Systems for the Non-Aligned and Other Developing Countries, Working Paper 17, Research and Information System for the NonAligned and Other Developing Countries (RIS), New Delhi.

Clark, N., Yoganand, B., and Hall, A. (2002), 'New science, capacity development and institutional change: the case of the Andhra Pradesh Netherlands Biotechnology Programme (APNLBP)', International Journal of Technology Management and Sustainable Development, Vol 1, No 3, pp 220-234.

Commandeur, P. (1997), 'The DGIS Special Programme on Biotechnology', Biotechnology and Development Monitor, No 31, p 611.

Dhar, B. (2002), 'Globalization and the international governance of modern biotechnology regulating biotechnology in India', Website: http://www.ids.ac.uk/ids/env/PDFs/Dhar\%20India. pdf.

Jain, H. K. (1999), 'Time for resurgence of public sector agricultural research', Biotechnology and Development Monitor, No 39, September, p 24.

Kenney, M. (1995), 'University-industry relations in biotechnology', in Fransman, M., ed, The Biotechnology Revolution? Blackwell Publishers, Oxford, pp 302-310.

Khush, G. S. (2002), 'Food security and poverty alleviation through application of biotechnology and through international collaboration', keynote address delivered during the International Seminar on 'Biotechnological Interventions for Dryland Agriculture Opportunities and Constraints', 18-20 July, organized by Andhra Pradesh Netherlands Biotechnology Programme, Institute of Public Enterprise, Hyderabad.

Pakki Reddy, G., and Janaki Krishna, P. S. (2002), 'Participatory approaches in agricultural research: a case study of the Andhra Pradesh Netherlands Biotechnology Programme', Management Extension Research Review, Vol 3, No 1, January-June, pp 1327.

Pimbert, M. (1994), 'The need for another research paradigm', Seedling, Vol 11, No 2, pp 20-26.

Pray, C. E., Ramaswanni, B., and Kelley, T. (2001), 'The impact of economic reforms on R\&D by the Indian seed industry', Food Policy, Vol 26, No 6, pp 587-598.

Raina, Rajeshwari. (2003), 'Innovation capability for agrobiotechnology: policy issues', Biotechnology and Development Monitor, No 50, March, pp 29-31.

Rao, Hanumantha C. H. (1987), 'Science and technology policy: an overall view and broader implications', in Agricultural Development in India: The Next Stage, Indian Society of Agricultural Economics, Bombay, pp 27-31.

Rao, S. R. (2002), 'Indian biotechnology developments in public and private sectors - status and opportunities', Website: http://www.ris.org.in/abdr_nov1.pdf.

Ruivenkamp, G. (2003), 'Tailor-made biotechnologies for endogenous developments and the creation of new networks and knowledge means', Biotechnology and Development Monitor, No 50, pp 14-16.

Seshia, S., and Scoones, I. (2003), Tracing Policy Connections: The Politics of Knowledge in the Green Revolution and Biotechnology Eras in India, IDS Working Paper 188, Website: http:/www.ids.ac.uk/ids/bookshop/wp/wp188.pdf.

Shiva, Vandana, and Ramprasad, Vanaja (1993), 'Vulnerabilities in the seed supply system', in Cultivating Diversity, Biodiversity 
Conservation and Seed Politics, Research Foundation for Science, Technology and Natural Resource Policy, Dehra Dun, pp 1944

Syngenta (undated), 'The socio-political impact of biotechnology in developing countries', Website: http:/www.syngentafoundation.com/

biotechnology_developing_countries.htm.

Witcombe, J. R. (1996), 'Participatory approaches to plant breeding and selection', Biotechnology and Development Monitor, No 29, p 26. 